\title{
Resiliência Financeira no interior da Amazônia: uma análise a partir da ótica da Volatilidade dos Gastos Públicos
}

Financial Resilience in the interior of the Amazon: an analysis from the perspective of Public Expenditure Volatility

\author{
Rayanne de Lima ${ }^{1}$ \\ Mario Vasconcellos Sobrinho ${ }^{2}$ \\ Vanessa Silva Fernandes ${ }^{3}$ \\ Julia Oliveira Silva ${ }^{4}$ \\ Camila Trindade Costa ${ }^{5}$
}

\section{Resumo:}

Este artigo tem o objetivo de analisar aspectos de resiliência financeira nos gastos públicos idiossincráticos dos municípios da região do Rio Capim no interior do Estado do Pará, observados a partir da volatilidade das despesas públicas no âmbito da assistência social e nas despesas com pessoal. O recorte temporal restringe-se aos anos de 2019 e 2020, anos decisivos em ambiente de impactos externos (crise) e de período político municipal. A metodologia utilizada consiste em análise qualitativa documental com vistas à pesquisa exploratória e descritiva de cunho, principalmente, interpretativo. Uma das principais conclusões é que as análises foram direcionadas apenas para alguns municípios considerados outliers no processo resiliente, o que não deveria ser uma exceção. A grande maioria dos municípios analisados seguiu a lógica explicada pela Teoria dos Ciclos Políticos, na qual os gastos públicos são direcionados com base na manutenção do poder.

Palavras-chave: Volatilidade dos gastos públicos. Resiliência Financeira. Despesa Pública.

\begin{abstract}
:
This article aims to analyze aspects of financial resilience in the idiosyncratic public expenditures of the municipalities of the Rio Capim region in the interior of the State of Pará, observed from the volatility of public expenditures in the scope of social assistance and personnel expenses. The time frame is restricted to the years 2019 and 2020, decisive years in an environment of external impacts (crisis) and municipal political period. The methodology used consists of qualitative document analysis with a view to exploratory and descriptive research, mainly of an interpretive nature. One of the main conclusions is that the analyzes were directed only to some municipalities considered outliers in the resilient process, which
\end{abstract}

\footnotetext{
${ }^{1}$ Doutoranda em Administração pela UNAMA. Professora efetiva da Universidade Federal Rural da Amazônia. E-mail: rayanelimacont@gmail.com

2 E-mail: mariovasc25@gmail.com

3 E-mail: vanessa.f.pgm@gmail.com

4 E-mail: juliaoliveira567@yahoo.com

5 E-mail: camila.hds@hotmail.com
} 
should not be an exception. The vast majority of the analyzed municipalities followed the logic explained by the Theory of Political Cycles, in which public spending is directed based on the maintenance of power.

Keywords: Volatility of public spending. Financial Resilience. Public Expenditure.

\section{Introdução}

O Brasil e o mundo vêm passando por um período adverso nos últimos meses desde que surgiu, na China, um vírus que causa uma doença de infecção respiratória chamada de Coronavírus (COVID-19). A Organização Mundial da Saúde (OMS) declarou situação de Emergência de Saúde Pública de Importância Internacional (ESPII) em 30 de janeiro de 2020, devido ao alto grau de contágio que o vírus possui e em 03 de fevereiro de 2020, por meio da portaria número 188 do Ministério da Saúde, foi declarado pelo Estado brasileiro "Emergência em Saúde Pública de Importância Nacional (ESPIN) em decorrência da Infecção Humana pelo novo Coronavírus (2019-nCoV)".

A partir da emergência em saúde pública, muitas medidas precisaram ser tomadas para que não houvesse maiores danos à população, dentre as quais pode-se destacar as medidas de isolamento, distanciamento social e quarentena (BRASIL, 2020). O governo federal, por meio dos ministérios, também deliberou sobre áreas como saúde, educação e assistência social, emitindo diversas normas para indicar como se daria o funcionamento ou não dessas políticas públicas. Ante às medidas de freamento de contágio dos vírus, dois setores sofreram diretamente seus impactos: o setor da saúde, tendo sido o guardião de frente neste sentido e a assistência social, que, indiretamente, em virtude do isolamento e lockdown, sentiram a necessidade de suporte financeiro, alimentício e de higiene sanitária.

Neste cenário de acentuação da crise, a assistência social não podia ser ignorada. A Lei $n^{\circ}$ 13.979/20 garante isso em seu parágrafo $1^{\circ}$, inciso II do Art. $3^{\circ}$ onde afirma que "a assistência social e atendimento à população em estado de vulnerabilidade são serviços públicos e atividades essenciais indispensáveis ao atendimento das necessidades inadiáveis da comunidade", e, para que este ideal não seja esquecido, a portaria $\mathrm{n}^{\circ} 54$, de $1^{\circ}$ de abril acrescenta que "deve-se assegurar a continuidade da oferta de serviços e atividades essenciais da Assistência Social voltados ao atendimento da população mais vulnerável e em risco social, observando-se medidas e condições que garantam a segurança e a saúde dos usuários e profissionais do SUAS".

Em virtude disto, medidas financeiras foram necessárias para garantir o funcionamento desse mecanismo, principalmente a nível municipal, como realocação/remanejamento de recursos para custear benefícios eventuais (cestas básicas, auxílio funeral), Equipamentos de Proteção Individual - EPIs, aparelhos respiratórios, dentre vários outros itens necessários em um cenário de pandemia. Mediante o exposto, observa-se que a pandemia causou um "desalinhamento" no funcionamento e consequentemente no que estava previsto para ser executado a nível municipal, na Lei Orçamentária Anual. Tratou-se de um impacto externo que não possuía previsibilidade orçamentária nem de gestão para enfrentar tal choque.

Nesse contexto, a literatura sobre resiliência financeira atua no sentido de encontrar subsídios empíricos que orientem os gestores a lidar com boas práticas de gestão orçamentária em ambientes adversos e passíveis de fortes impactos financeiros, adaptadas às necessidades locais do ambiente, o que, neste trabalho, refere-se ao ambiente amazônico. A partir disto, a resiliência financeira, pode, portanto, ser compreendida como a capacidade do município de se prevenir, recuperar e/ou se adaptar a situações inesperadas, conforme Oliveira et. al. (2019) e Lima e Aquino (2019). 
Atrelado aos conceitos de resiliência financeira, o presente estudo busca não só analisar os efeitos que a pandemia ocasionou às contas públicas, mas observar se tais municípios agiram de modo resiliente. Para isto, dois grupos de despesa foram analisados: as despesas com pessoal e as despesas com assistência social. A lógica para análise das despesas de pessoal é justificada pela Teoria dos Ciclos Políticos, que nos fornece subsídios para afirmar que os gastos com pessoal sofrem comportamentos previsíveis em anos políticos.

Ora, se estamos em um ambiente de crise imprevisível que afeta a assistência social e demanda mais recursos e contratação de pessoas, é cabível a interpretação de que haja uma diminuição ou pelo menos estabilização de despesas com pessoal, quando comparado às despesas de um ano não pandêmico, pelo menos no setor administrativo. Outro fato que aguça a investigação é o cenário da região do Rio Capim ser composta por 13 (treze) municípios, e, dentre eles, 8 (oito) não tiveram suas contas aprovadas, alertando para indicativos de corrupção, o que pode ser melhor visualizado em contexto de crise, dado que envolve transferências de recursos federais não vinculados, orçamento paralelo e novas demandas urgentes. Tal relação pode ser melhor analisada quando comparada ao ano de 2019 , ano considerado neutro às fontes de impactos analisadas.

A região amazônica, principalmente a região do Rio Capim, detalhada na fundamentação, faz parte de um todo que possui necessidades específicas de locomoção, economia, cultura e alimentação que constituem suas características regionais. Tais peculiaridades direcionam este estudo a uma realidade de um povo e de um local pouco explorado quando falamos de gestão pública e desigualdades sociais.

Em virtude destes fatores explicitados, este estudo busca sua essência na contribuição para o aprimoramento dos gastos públicos relacionados à assistência e com pessoal, visando colaborar academicamente para conceitos relacionados à resiliência financeira em virtude de lacuna teórica em ambiente amazônico neste tema, e, principalmente, no ideal de fornecer visibilidade à região Amazônia, trazendo-a ao foco dos estudos científicos que colaborem para finalidade prática financeira da gestão pública, mas que levem em consideração suas especificidades de sujeitos e culturas. Para alcançar tais finalidades, busca-se responder à seguinte pergunta: a volatilidade dos gastos públicos na área da assistência social e com pessoal no interior do Pará, especificamente na região do Capim, seguiu uma lógica resiliente em contexto de crise?

Este artigo se desenvolve da seguinte maneira: os próximos tópicos tratam de contribuições bibliográficas que nos auxiliam a entender o fenômeno do ciclo dos gastos públicos e contextualizam o cenário de pandemia na amostra estudada. Depois, tratamos dos procedimentos metodológicos e coletas de dados, por fim, analisamos os dados e traremos nossas conclusões, respectivamente.

\section{Fundamentação teórica}

\subsection{A crise financeira e social no interior da Amazônia em decorrência da COVID-19}

A região da Amazônia compreende todo o Norte do Brasil, com exceção de parte do Tocantins. Neste ambiente amazônico e principalmente em algumas regiões, as características sociais, econômicas e climáticas diferem-se essencialmente do restante do Brasil dado que estamos lidando com um clima predominantemente equatorial que apresenta maior umidade, elevadas temperaturas e com fortes chuvas durante todo $\mathrm{o}$ ano. Tais características influenciam o modus vivendi da maioria dos nortistas, que concentram suas atividades sociais e econômicas atreladas aos rios e à agricultura. 
Todavia, realizar uma análise minuciosa sobre as características do ambiente amazônico não é o ponto que pretendemos aprofundar para fins de sustentação deste estudo. O que discutimos aqui é a intensidade e abrangência da crise desencadeada pela COVID-19 que culminaram em crises fiscais, orçamentárias e financeiras na região Norte, especificamente na Região do Rio Capim, de modo que, a partir de tal explanação, possa ser fornecido ao leitor, subsídios teóricos que justifiquem (ou não) os atos de gestão durante a crise.

A partir deste objetivo teórico, segundo o boletim epidemiológico oficial divulgado pelo governo da saúde, a região Norte, conta até o momento (junho 2021) com mais de 31.000 mortes confirmadas pelo coronavírus, com um dos maiores níveis de infecção em relação ao número da população quando comparado a outras regiões do Brasil, chegando ao índice até o momento de 7,3\% de toda a população da região norte, ou seja, 1.131.443 de pessoas infectadas.

Em relação ao afunilamento amostral que buscamos estudar, a região do Pará também faz parte deste contexto. Com uma população total de 8,074 milhões, 457 mil tiveram contato com o vírus, tendo mais de 12.000 mortos no estado. A região do Capim conta com um total de 16 municípios. Esses municípios representam $32 \%$ dos casos registrados no estado, número representativo, se considerarmos que esta região não inclui a maior cidade do Estado, Belém do Pará.

A Região de Integração do Rio Capim é composto por 16 municípios: Abel Figueiredo, Aurora do Pará, Bujaru, Capitão Poço, Concórdia do Pará, Dom Eliseu, Garrafão do Norte, Ipixuna do Pará, Irituia, Mãe do Rio, Nova Esperança do Piriá, Ourém, Paragominas, Rondon do Pará, Tomé-Açu e Ulianópolis, localizada na região Nordeste do Pará, tem $62.161,90 \mathrm{~km}^{2}$ de extensão territorial o que representa $5 \%$ da área total do Pará e aproximadamente 695.360 habitantes (FAPESPA, 2020).

Esta região faz parte do Nordeste Paraense e possui como principais atividades econômicas: pesca, agricultura, fruticultura, cadeia produtiva da mandioca, feijão-caupi, mineração, pecuária, produção de leite e derivados, assim como, chamado cultivo florestal e indústria cerâmica (SEIR, 2011). Esta região faz parte de uma grande mesorregião biogeográfica, com especificidades socioculturais e ecológicas (CORDEIRO, ARBAGE, SCHWARTZ 2017).

A situação histórica e geográfica influenciou no sistema de manejo do solo, refletindo no valor cultural, social, econômico, político e ambiental da população local do Nordeste Paraense (CORDEIRO, ARBAGE, SCHWARTZ, 2017). As atividades econômicas nos municípios da mesorregião foram expandidas pela malha viária e a bacia hidroviária, permitindo maior facilidade à comercialização da produção (PEREIRA, 2017).

De acordo com Pereira (2017), os municípios do Nordeste Paraense evidenciam diferentes estágios de desenvolvimento populacional, melhorias na urbanização, saneamento, saúde e produção agropecuária. Apesar de haver algumas características socioeconômicas favoráveis, a mesorregião ainda requer ações do poder público que sejam capazes de solucionar problemas históricos que prejudicam a qualidade de vida e o desenvolvimento econômico da população residente.

Os municípios que compõem a Região do Rio Capim possuem características econômicas e climáticas similares. Assim, em decorrência do grande impacto sanitário que afetou a gestão pública, medidas de contenção e manutenção da máquina pública precisaram ser tomadas. Porém, a prestação de contas, passou a ser o principal desafio desta região. E isto não é fato recente, mas ganhou uma outra dimensão com os gastos dos últimos tempos.

O cenário que chama a atenção é o fato de 8 (oito) dos 15 (quinze) municípios da região terem suas contas reprovadas por indicativos de corrupção. Hoje, a principal dificuldade para contextualizar a região neste cenário e identificar os gastos públicos para fins desta investigação, foi a transparência, pois faltam critérios para divulgação dos gastos públicos e, aparentemente, existe também uma fiscalização falha. A 
probabilidade de ambientes de corrupção pode afetar a sociedade na sua qualidade de vida, no acesso aos serviços públicos de qualidade e o mais agravante, intensificando os efeitos econômicos e sociais que a crise sanitária produziu na região.

\subsubsection{Gastos com Assistência Social}

A assistência social é garantida por meio da Constituição Federal de 1988. Ela faz parte do tripé do Sistema de Seguridade Social juntamente com a previdência e a saúde, sendo dever do estado e direito do cidadão (BRASIL, 1988). Visa garantir acesso a serviços e benefícios sociais a fim de possibilitar ao cidadão o enfrentamento de situações de risco social ou privações de direitos e deve ser realizada através de um conjunto integrado de ações de iniciativa pública e da sociedade, para garantir o atendimento às necessidades básicas da população (BRASIL, 1993). Para atender aos objetivos dessa política, ela está dividida em dois tipos de proteção: a proteção social básica e a proteção social especial.

Segundo a Tipificação Nacional dos Serviços Socioassistenciais de 2009, a Proteção Social Básica visa prevenir situações de vulnerabilidade e risco social por meio do desenvolvimento de potencialidades e aquisições e do fortalecimento de vínculos familiares e comunitários. O CRAS - Centro de Referência da Assistência Social, é a unidade pública destinada à articulação dos serviços socioassistenciais no seu território de abrangência e à prestação de serviços, programas e projetos às famílias. Já a Proteção Social Especial, ainda de acordo com a Tipificação, tem por objetivo contribuir para a reconstrução de vínculos familiares e comunitários, a defesa de direito, o fortalecimento das potencialidades e aquisições e a proteção de famílias e indivíduos para o enfrentamento das situações de violação de direitos.

Discutir esse contexto de essencialidade em um cenário pandêmico, destaca e justifica as possíveis mudanças orçamentárias na execução dos gastos públicos neste setor. A assistência social é encarada como principal ferramenta para atenuação das desigualdades sociais e garantia mínima de condições de vida. Sem a devida atenção a este setor, não seria possível o combate à pandemia, sem maiores danos sociais, provenientes, inclusive, de medidas restritivas de isolamento e lockdown.

\subsubsection{Gastos com Pessoal}

Sobre o que preconiza a literatura com gastos de pessoal, a Lei de Responsabilidade Fiscal estabelece o percentual do pagamento dessas despesas com as receitas correntes líquidas e determina o limite com os gastos destinados a essa área (SANTOS, CARVALHO E NASCIMENTO, 2020). De acordo com o fixado pela LRF (2000) em seu artigo 19, o gasto total com pessoal no âmbito municipal não deve exceder $60 \%$ da receita corrente líquida em cada período de apuração, esse limite foi estabelecido como forma de manter um controle dos gastos, para que os gestores não extrapolem e contraiam dívidas desnecessárias, visto que segundo Giovanini (2019) nos anos antecedentes à Lei de Responsabilidade Fiscal estava ocorrendo uma desordem nas finanças públicas, acarretada pela diminuição da receita tributária que aconteceu durante esse período. Conforme disposto na LRF (2000) nem todas as despesas com pessoal são contempladas pelo limite estabelecido de $60 \%$ com relação as receitas correntes líquidas, contudo desse limite fixado $54 \%$ é destinado ao Poder Executivo e $6 \%$ ao Poder Legislativo.

As despesas com pessoal têm tido um acréscimo significativo ao longo dos anos, causando um impacto considerável nas finanças públicas, pois principalmente nos municípios com poucos habitantes e economicamente pequenos os gastos com folha de pagamento dos funcionários públicos vêm sendo constantemente incrementado, e em alguns casos o valor de receitas arrecadadas é menor do que o valor 
das despesas realizadas com pessoal, o que acarreta num desequilíbrio orçamentário (BERLT, BENDER FILHO E TRISTÃO, 2014; DAMAZIO, 2019).

De acordo com Giovanini (2019), a Lei de Responsabilidade Fiscal demonstrou ser eficaz quando se trata de um curto período de tempo, entretanto a longo prazo ela ocasionou alguns problemas nas despesas públicas, pois estimula o aumento dos gastos com funcionários e desmotiva os investimentos. $O$ aumento dessas despesas com pessoal é resultado da elevação do número de funcionários para cargos já ocupados e maior facilidade para progressão de carreira e aumento de salários, sendo priorizadas as pessoas com aproximação política, os eleitores e clientes, principalmente em cargos comissionados ou de confiança (GIOVANINI, 2019), em situações como estas, os gestores geralmente empregam pessoas que tenham lhe proporcionado ou possam proporcionar algum tipo de benefício.

Conforme Berlt, Bender Filho e Tristão (2014), com o surgimento da LRF as contas da administração pública puderam ser regulamentadas de forma mais eficaz, dando foco ao orçamento, planejamento e controle e exigindo a obrigatoriedade da prestação de contas, ocasionando, por conseguinte, o aumento da transparência, suas normas e diretrizes devem ser seguidas pela União, estados e municípios (GIOVANINI, 2019).

Porém, mesmo com toda a regulamentação que trata sobre gastos de pessoal, os limites estabelecidos são comumente ultrapassados, como o caso da nossa amostra, tratados na análise de resultado. $O$ próximo tópico versa sobre o comportamento dos gastos de pessoal, explicado pela Teoria dos Ciclos Políticos.

\subsection{A volatilidade de Gastos Públicos em período eleitoral explicada pela Teoria dos Ciclos Políticos}

A tomada de decisão dos gestores alinhada, especificamente, à discussão de ciclos econômicos foi levantada na literatura internacional de forma seminal por Kalecki (1943), quem constatou que o governo aumentava a oferta de empregos e gastos públicos, mesmo contrariando as indústrias que declinavam da política do pleno emprego, indicando a intervenção do Estado na economia por meio da oferta de empregos. Depois, a Teoria do Ciclo Político começou a ser montada por Downs (1957). Em comparação com o setor privado, concluiu-se que as políticas públicas tinham cunho pessoal do gestor, visando à manutenção no poder.

Nordhaus (1975), em sua teoria, defendeu que os eleitores possuem memória decadente, sendo influenciados em curto prazo, estando mais sujeitos às ações dos policymakers, que buscam convencer os eleitores por meio de ações capazes de cativá-los nos períodos pré-eleitorais. Nos estudos de Klein e Sakurai (2015) foi diagnosticado índices que se referem ao ciclo político, um deles diz respeito ao ciclo político oportunista; neste, os gestores direcionam gastos que influenciam suas chances de recondução em períodos eleitorais.

Pesquisas internacionais apontam para a presença de ciclos políticos nas eleições dos municípios. Por exemplo, na Colômbia (Drazen \& Eslava, 2010), nas Filipinas (Labonne, 2016), em Portugal (Veiga \& Veiga, 2007), todos esses estudos encontraram influência positiva na recondução dos prefeitos, ao direcionarem a execução orçamentária para despesas mais visíveis aos eleitores. No Brasil, Cavalcante (2016) analisou a relação do desempenho fiscal e a reeleição, em quatro legislaturas, de 1997 a 2012. Concluiu que os eleitores brasileiros bonificam com a recondução ao cargo aqueles prefeitos que elevam os gastos com investimentos, bem como os eleitores os punem quando aplicam políticas que visam a melhores resultados fiscais, empenhando-se em aumentar arrecadação de tributos.

Os estudos nacionais ratificam a existência e relevância da teoria de ciclos e reeleição na relação com gastos públicos em anos políticos, aplicando seus efeitos práticos na reeleição do prefeito ou do partido 
(Vicente \& Nascimento, 2012; Gonçalves et al., 2017; Cavalcante, 2016; Klein \& Sakurai, 2015; Sakurai \& Menezes, 2008). Esta constatação pôde nos guiar durante os passos da pesquisa, e direcionou principalmente o estudo para gasto com pessoal, em virtude do ciclo político e com assistência social, dada a intensificação nesta área gerada por medidas de freamento dos efeitos do vírus.

A partir deste cenário e baseado no comportamento das despesas públicas, foi analisado como os gastos públicos se comportaram em anos políticos dada as urgências que o ambiente pandêmico proporciona. $E$ quando é falado sobre gestão dos recursos públicos, falamos sobre munícipio resiliente, como tratado no próximo tópico.

\subsection{Resiliência Financeira}

A resiliência financeira, ligada à gestão pública, consiste na capacidade do ente de conhecer suas vulnerabilidades, de se precaver e recuperar-se de choques financeiros ocasionados em momentos de crises, conforme Lima e Aquino (2019), ou seja, um ente resiliente utiliza de estratégias para que, no caso da ocorrência de crises, esteja preparado para enfrentá-las, de forma a não ter tantos prejuízos quanto os entes não resilientes. Neste cenário de pandemia, a resiliência traz literatura sobre como entes considerados resilientes agem diante da adversidade.

Uma organização resiliente tem grande capacidade de enfrentamento e superação de impactos, sejam eles financeiros, sociais ou ambientais que culminam em perdas financeiras e orçamentárias. Os principais pontos dentro do conceito de resiliência financeira são a vulnerabilidade percebida, a capacidade de antecipação de choques ou pressões e a capacidade de reação a eles (Batista e Cruz, 2019; Lima e Aquino, 2019).

Estando a resiliência financeira estritamente ligada aos choques financeiros, estes, de acordo com Batista e Cruz (2019), caracterizam-se por serem inesperados e inevitáveis e por ocasionarem grandes problemas aos gestores públicos, por conta dos impactos que causam. Em um ente não resiliente, os choques financeiros resultantes de crises inesperadas podem ocasionar grandes danos, o que faz ser bastante necessária a atuação dos gestores para tentar solucionar as deficiências na gestão que tornam os entes vulneráveis.

A vulnerabilidade percebida, dentro do conceito de resiliência financeira, refere-se ao tanto que o ente se considera sujeito às crises e aos choques financeiros, e essa vulnerabilidade está ligada a diversos fatores internos e externos, como, por exemplo, a incerteza da arrecadação das receitas previstas e a dependência que as organizações públicas têm de recursos externos (Batista e Cruz, 2019). Em um cenário de crise como a pandemia, a resiliência financeira foca nas potencialidades locais como modo de fomento à economia e no fortalecimento das vulnerabilidades, para auxiliar no enfrentamento destas adversidades. Enxugar a máquina pública, pensar em otimizações no recolhimento de receitas e fomentar a economia são algumas atitudes resilientes (LIMA e AQUINO 2019).

Já a capacidade de antecipação aos eventos, está ligada à disponibilidade de mecanismos que possibilitam aos gestores públicos identificarem as vulnerabilidades dos entes, de maneira a tentar resolvê-las e preparar-se antecipadamente para prováveis choques financeiros e os impactos causados por eles. Portanto, a capacidade de antecipação refere-se à identificação de falhas e vulnerabilidades, previsão de possíveis crises e elaboração de ideias para o caso da ocorrência de danos, criação de estratégias para que caso as crises previstas venham a acontecer, o ente não sinta tanto impacto em suas finanças.

O ponto importante dentro do conceito de resiliência financeira, o qual vamos trabalhar neste artigo, é a capacidade de reação aos choques ou capacidade de enfrentamento. O período analisado busca 
compreender a resiliência financeira pela ótica da volatilidade dos gastos públicos no período de pandemia em relação a um ano não pandêmico. Isso implica analisar as oscilações dos gastos de modos a rastreálos e o observá-los pela ótica da resiliência.

Neste cenário, é de responsabilidade dos governantes públicos buscar solucionar e amenizar os impactos das crises e desenvolver estratégias que impulsionem novamente a economia, (BATISTA E CRUZ, 2019). Ainda conforme os autores, essas estratégias de enfrentamento envolvem a execução de atitudes referentes à tributação, aos gastos públicos e ao endividamento do ente, tendo em vista que algumas pesquisas demonstram que a capacidade que a organização pública tem de enfrentar os choques está essencialmente ligada às medidas tomadas em relação às receitas e despesas (BATISTA E CRUZ, 2019).

O que também concorda com a pesquisa de Aquino e Cardoso (2017), cujo resultado obtido foi que os municípios brasileiros pesquisados tomaram como medidas de enfrentamento à crise, a reorganização da arrecadação de receitas tributárias e a diminuição de despesas, principalmente as despesas com pessoal. É muito importante que os representantes públicos utilizem dessas medidas com relação ao aumento das receitas e a diminuição das despesas para o enfrentamento dos choques financeiros (BATISTA E CRUZ, 2019).

Nesse contexto, o impacto decorrente da crise desencadeada pela COVID-19 não pôde ser previsto, muito menos antecipado, mas sim enfrentado e sofrido adaptações. Por este motivo e baseado nos estudos apresentados durante a fundamentação, é que poderemos analisar se os municípios ora em análise podem ser considerados resilientes e agiram conforme o que preconiza a Teoria dos Ciclos Políticos.

\section{Metodologia:}

O estudo em questão busca analisar a volatilidade dos gastos públicos dos municípios da região do Rio Capim, interior do Estado do Pará, nas áreas de Assistência Social e com Pessoal, em período de pandemia da Covid-19 e em ano político. A pesquisa é de natureza estratégica e caracteriza-se como descritiva, tendo em vista que objetiva descrever e fazer uma análise da execução orçamentária dos gastos realizados com assistência e pessoal na região em estudo nos anos de 2019 e 2020. Possui uma abordagem qualitativa, que, de acordo com Prodanov e Freitas (2013), consiste na compreensão e interpretação de fenômenos que não podem ser quantificados, pois vêm da subjetividade e com vertente interpretacionista, pois, baseado nos comportamentos das despesas públicas e na fundamentação teórica, será deduzida a investigação.

O objeto de estudo foi a região do Rio Capim, pois, é uma região invisibilizada do ponto de vista acadêmico, com similaridades econômicas e sociais, e ainda, possui um agravante relacionado à transparência: um número de contas não aprovas dos municípios e a ausência de critério nas demonstrações das contas públicas principalmente em ano eletivo e pandêmico, no qual os municípios receberam recursos não vinculados aos seus fins, para o embate dos efeitos da COVID-19 e que aparentemente não foi tido nenhum cuidado quanto à sua accountability, no sentido de prestação de conta e responsabilização.

Para este estudo, teremos como amostra as informações obtidas nas demonstrações contábeis dos anos 2019 e 2020. Esses anos foram escolhidos não aleatoriamente, mas de modo estratégico: o ano de 2019 foi um ano considerado "normal", sem impactos relevantes que justificassem a utilização de créditos extraordinários, ou seja, calamidade pública, guerra ou comoção interna. Este ano, deveria pelo menos, seguir a Lei Orçamentária Anual planejada para o ano de 2019. Já o ano de 2020, além de ser um ano político, foi o ano em que a crise se alastrou e a qual perdura até o presente momento da escrita deste artigo. Portanto, analisando esses dois anos, será possível perceber a volatilidade dos gastos nestes dois 
âmbitos: assistência social e pessoal, a possível intensificação de gastos com pessoal em virtude de ano político e as estratégias de enfrentamento e gastos das prefeituras em assistência social, de modo resiliente.

Para chegar ao nosso objetivo, inicialmente foi realizada uma pesquisa bibliográfica em artigos que abordam o tema, com o objetivo de fazer um levantamento sobre o assunto e a segunda parte do trabalho constitui uma pesquisa documental, que de acordo com Lakatos e Marconi (2003), é elaborada apenas com documentos. Para tal pesquisa foram retirados do portal da transparência dos municípios, através dos sites eletrônicos das prefeituras, dados externos acerca das informações financeiras dos municípios, com o objetivo de identificar os gastos públicos efetuados na área da assistência social e na área de pessoal, o terceiro passo foi a relação entre os gastos públicos e o contexto político e sanitário.

Cabe salientar ao leitor que os dados de alguns municípios foram extraídos com muito sacrifício internamente entre as entidades, pois ainda não haviam sidos divulgados por motivos não aparentes.

\subsection{Tratamento dos dados}

Foram retirados da amostra, municípios que, em hipótese alguma, decidiram publicitar seus gastos financeiros e orçamentários, nem fornecê-los por solicitação. Depois, caso os municípios não apresentassem as demonstrações financeiras que tratam de todo o gasto relativo ao ano anterior, os dados foram coletados através da Lei Orçamentária Anual, exceto para o ano de 2020 que não havia, neste momento, consciência de estratégias para a pandemia.

Em seguida, foi necessário separar a variação de gastos com pessoal geral daquelas que foram referentes à assistência social, no sentido de inibir falsas interpretações sobre o aumento com despesa de pessoal e de retirar do efeito desses possíveis aumentos aqueles referentes à assistência social, que poderiam ser explicados pelas novas demandas em virtude da pandemia.

\section{Análise dos resultados:}

Nesta seção, trataremos da análise dos dados. A tabela abaixo mostra os dados relativos a gastos com pessoal do ano de 2019 e 2020.

Gráfico 1 - Demonstração dos Gastos com Pessoal

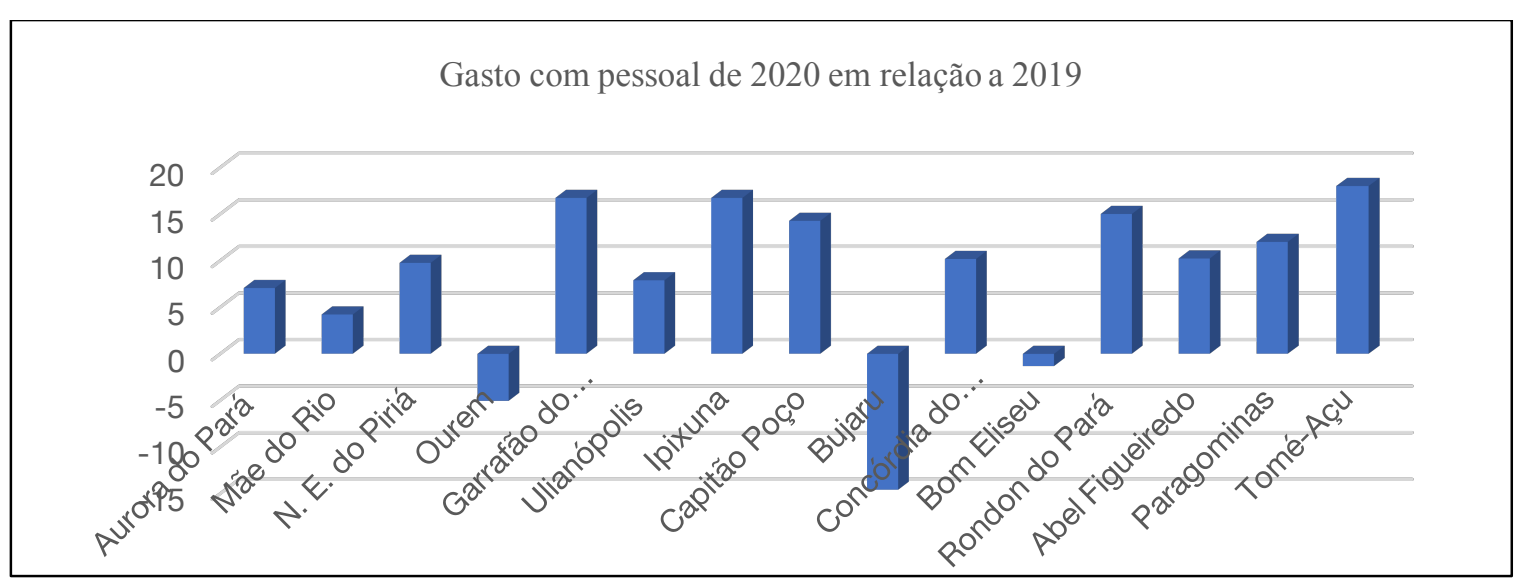


Fonte: elaboração do autor (2021)

Percebe-se que apenas dois municípios tiveram a pretensão de enxugar a máquina pública: Bujaru, que passou de 40.470.744,23 para 34.569.430,55 de gastos com pessoal, sendo recorde nesse sentido de diminuição, e Ourém, que de 14.183.378,66 com gastos com pessoal, foi para 13.468.529,52. Os outros municípios mantiveram o aumento de seus gastos mesmo em ano pandêmico, em especial as cidades de Tomé-Açu, Ipixuna e Garrafão do Norte, preservando uma média de $15 \%$ de aumento, que ultrapassa o limite de gastos estabelecidos pela Lei de Responsabilidade Fiscal.

No sentido de diminuir os efeitos do setor de saúde nesta alteração, foram retirados os gastos da saúde com pessoal, mesmo assim não foi observada alteração significativa. Este diagnóstico inicial corrobora com a Teoria dos Ciclos políticos apresentada na fundamentação a qual afirma que os gastos públicos, em especial com pessoal, são influenciados por anos políticos. Porém, neste caso, ainda há um agravante a este cenário: o impacto sanitário e social causado pela pandemia. Com urgência para compra de Equipamentos de Proteção Individual, de campanhas de conscientização sanitária, atrelado à queda significativa nas receitas originárias, dado o desestímulo da economia local, a última atitude que deveria ser realizada pelo gestor público é a inflação à máquina pública através de cargos de comissão, confiança e para atividade fim (administrativa).

A literatura sobre resiliência já nos alerta para este fato. Os choques externos que possam influenciar negativamente a gestão pública, devem estar munidos de políticas que visem o aumento da receita primária, em detrimento a gastos com pessoal. Tal manobra possibilita ao gestor probabilidades diferenciadas que busquem a estabilização e enfrentamento do impacto através das próprias receitas primárias. Selecionar/contratar pessoas com esse objetivo de estimular a renda local, não condiz com estratégia resiliente, pois nada assegura que os recursos ali inseridos retornarão ao município em forma de consumo, além de privilegiar determinada classe/população, intensificando a desigualdade.

A tabela abaixo mostra o quanto que desses aumentos de despesa com pessoal, referem-se a contratações no âmbito da assistência social. Tal extração foi realizada na intenção de buscar justificativas para os aumentos, uma vez que em ano pandêmico pode ter ocorrido a demanda por mais pessoas na assistência social.

Gráfico 2 - Demonstração dos Gastos com Pessoal da Assistência Social

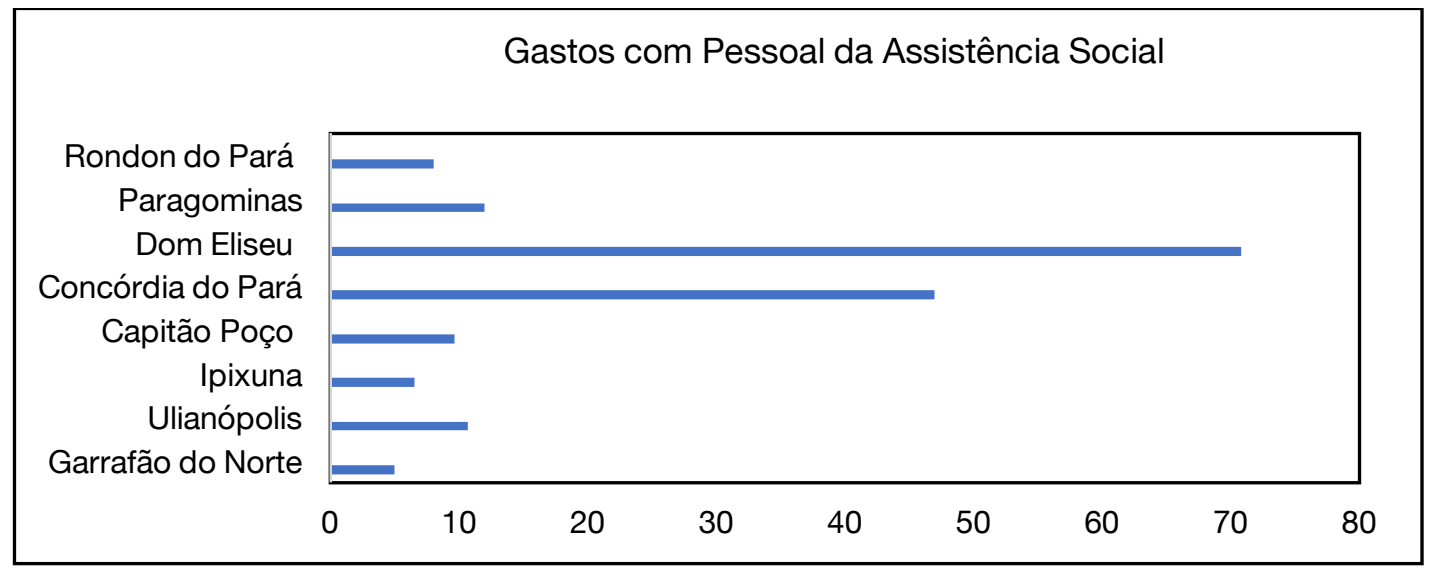

Fonte: Elaboração própria (2021) 
Os dados do gráfico 2 explicam a responsabilidade dos gastos com pessoal da assistência social na variação total dos gastos com pessoal do município. Esta análise tem a intenção de buscar justificativas para os aumentos, uma vez que em ano pandêmico pode ter ocorrido a demanda por mais pessoas na assistência social.

De acordo com os dados, apenas o município de Dom Eliseu e Concórdia do Pará tiveram suas variações de gastos com pessoal, explicados pela despesa com assistência social em uma porcentagem representativa - acima de $50 \%$. Os outros municípios mantiveram suas variações por média de $10 \%$ ou menos. Os municípios restantes não apresentaram nenhum aumento com despesa de pessoal na assistência social.

Esta análise mostra que, apesar de ter havido aumento significativo nas despesas com pessoal entre os municípios da região do Capim, pouco é explicado pelos acréscimos na saúde e na assistência social, o que traz indicativos de que as despesas que foram acrescentadas em ano pandêmico não tiveram o caráter anticíclico de frear o contágio do vírus e sim para alimentar o ciclo político visando a manutenção política no poder.

O gráfico abaixo mostra os gastos exclusivos da assistência social em um contexto geral. Isso inclui a secretaria (pessoal e ações) e os programas que a assistência social viabiliza, tanto com o fundo municipal de assistência social como recursos próprios. A intenção é os gastos que, por ventura, não foram identificados na variação com pessoal da assistência social, sejam percebidos através de ações, como por exemplo, cestas básicas, ações com idosos, crianças e etc.

\section{Gráfico 3 - Demonstração dos Gastos com Assistência Social}

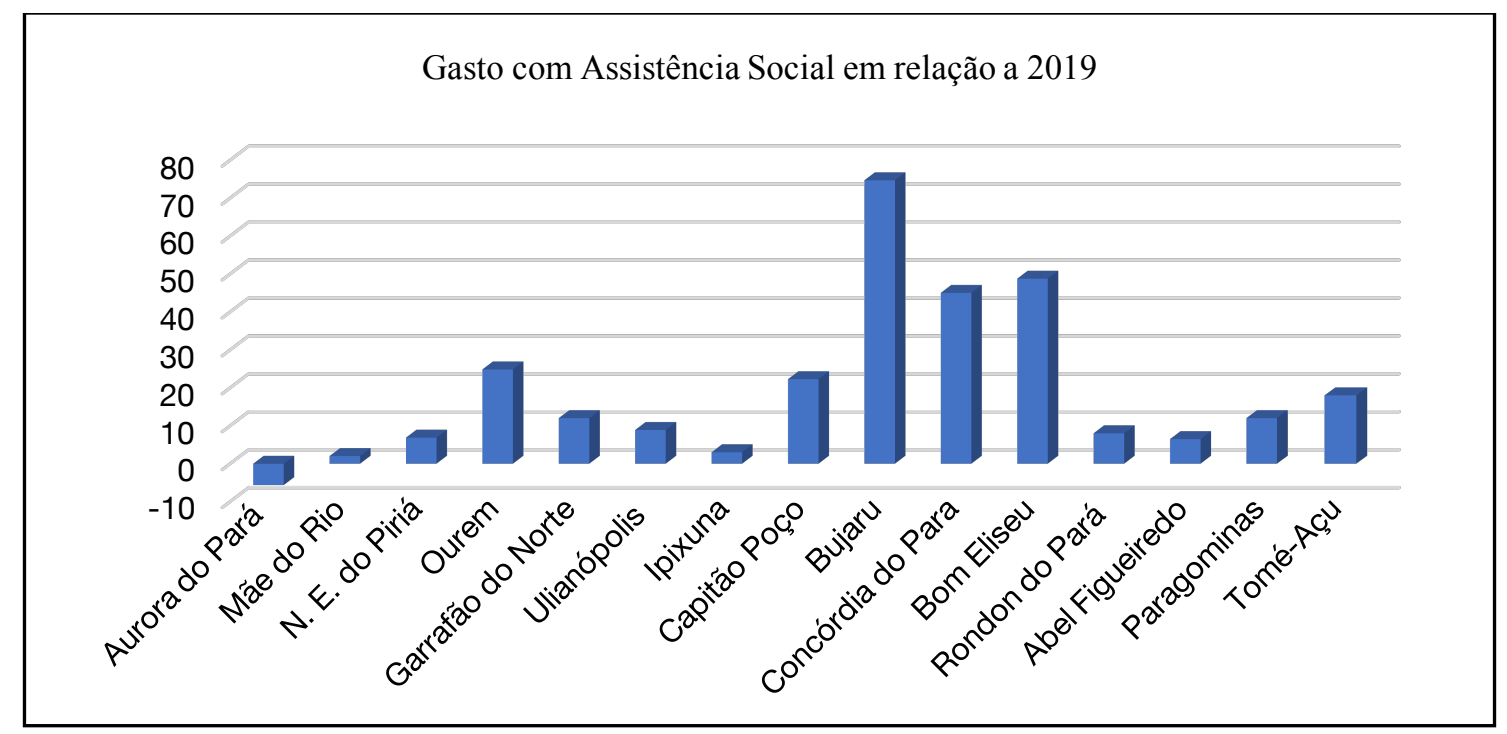

Fonte: Elaboração própria (2021)

Os gastos com assistência social em relação à 2019 mostram que não houve aumento significativo de despesas no setor, exceto em três municípios: Dom Eliseu, Concórdia do Pará e, principalmente, Bujaru que aumentou suas despesas em $74,68 \%$ em relação ao gasto de 2019 , indicando que os esforços foram principalmente empreendidos em ações da assistência social. Os outros municípios, embora estivessem em ano pandêmico que exige uma atenção especial ao âmbito da saúde e da assistência social, não focaram suas ações neste sentido uma vez que não houve aumento das demandas, nem remajemaneto dos recursos. 
Quando o gráfico 3, comparado ao gráfico 1, percebemos latente diferença entre os incrementos de recursos na área da assistência social e com pessoal geral, pois, enquanto que a média de aumento dos salários geral seguiu de $15 \%$ para mais, o aumento com assistência social total seguiu uma faixa de $5 \%$ com alguns "outliers" positivos. Essas variações corroboram com a Teoria dos Ciclos Políticos que afirma que gastos com pessoal tendem a aumentar significativamente em anos políticos em detrimento às outras áreas.

Nesse contexto, a resiliência financeira está relacionada à lógica da gestão pública no manuseamento de recursos que visam a atenuar e enfrentar os impactos externos que influenciam a sociedade. A antecipação dos choques advindos pela COVID-19, neste caso tratado no artigo, não poderia ser previsto, mas, poderia ser atenuado e cocomitantemente enfrentado com ações que buscassem a manutenção das condições mínimas de saúde e bem-estar. Essas ações implicam em gastos e para isso, todos os municípios receberam repasse não vinculado do governo federal.

Outro agravante a esta problemática da volatilidade dos gastos públicos nestes dois anos, é a questão destes repasses, que, segundo o Programa Federativo de Enfrentamento ao Coronavírus no Estado do Pará, o município de Abel Figueiredo recebeu 747.541,99, Aurora do Pará, 3.151.260,54, Bujaru 2.929.431,43, Capitão Poço, 5.460.555,92, Concórdia do Pará, 3.350.363,74, Dom Eliseu, 6.005.173,54, Garrafão do Norte, 2.621.123,15, Ipixuna do Pará, 6.440.988,31, Irituia 3.273.135,83, Mãe do Rio, 3.024.457,95, Nova Esperança do Piriá, 2.148.705,57, Ourém, 1.794.141,00, Paragominas, 11.377.540,82, Rondon do Pará, 5.264.871,67 Tomé-Açu, 6.380.050,66 e Ulianópolis, 5.953.989,94.

Ou seja, um total de 63.969.342,12 de recursos não vinculados para o combate aos efeitos do Coronavírus em 2020, porém, como pôde ser observado, a diferença através dos demonstrativos do ano de 2019 para o ano de 2020 não indicam esforços representativos no âmbito da saúde, muito menos da assistência social, incluindo gastos com pessoal. O "Orçamento de Guerra" como foi tratado no congresso em relação às emendas, carece de transparência específica no sentido de demonstrar tais ações como em um orçamento paralelo, o que, até o momento, não foi identificado por parte dos municípios analisados.

\section{Conclusões:}

O objetivo deste artigo foi analisar a resiliência financeira dos municípios da região do Rio Capim pela ótica da volatilidade dos gastos públicos, ancorados nos preceitos da Teoria dos Ciclos Políticos que explicam o comportamento dos gastos públicos em anos políticos. O recorte temporal foi durante os anos de $2019 \mathrm{e}$ 2020, fato que justifica a utilização da Teoria dos Ciclos Políticos em conjunto à literatura sobre resiliência.

A região do Rio Capim localiza-se no interior do Pará, possui similaridades climáticas e econômicas entre os municípios. Percebeu-se que nesta região há uma precariedade notória dentre os requisitos mínimos de prestação de contas - accountability -, principal desafio na consecução desta pesquisa, fato que pode corroborar com a realidade de 8 municípios com contas públicas não aprovadas na região. Tal inquietação direcionou a pesquisa para esta região, uma vez que os municípios somados receberam mais de 60 milhões de recursos não vinculados para combate à pandemia.

As demonstrações contábeis e informações nos portais de transparência foram utilizados para fins de análise dos comportamentos dos gastos públicos. Foi observado que os gastos com pessoal tiveram um aumento médio de $15 \%$ em relação à 2019, exceto por dois municípios: Ourém e Bujaru. Este diagnóstico inicial corrobora com a Teoria dos Ciclos políticos apresentada na fundamentação teórica, a qual afirma que os gastos públicos, em especial com pessoal, são influenciados por anos políticos.

Sobre a ótica da resiliência, os municípios fugiram do padrão ideal resiliente, pois, os impactos externos (neste caso, pandemia) que possam influenciar negativamente a gestão pública, devem estar munidos de 
políticas que visem o aumento da receita primária, em detrimento a gastos com pessoal. Tal manobra possibilita ao gestor probabilidades diferenciadas que busquem a estabilização e enfrentamento do impacto através das próprias receitas primárias.

Foram tirados desse último resultado, os gastos com pessoal na área da saúde, mas não houve diferença significativa, permanecendo uma média de até $2 \%$ em relação ao ano de 2019 . Na intenção de investigar se o aumento com gastos de pessoal foi referente à assistência social, o que poderia ser justificado pela pandemia, percebeu-se que apenas o município de Dom Eliseu e Concórdia do Pará tiveram seus aumentos de pessoal relacionando à assistência social, de modo significativo, estando em uma média de $50 \%$, esse resultado é representativo. Porém, os outros municípios tiveram baixíssimas taxas de explicação nas variações, com uma média de $9 \%$.

Portanto, por eliminação, percebe-se que as variações de aumento de pessoal referiram-se às secretarias de infraestrutura, administração, cultura e esporte, sem relação direta identificada com o combate a pandemia.

A resiliência financeira preconiza os gastos com assistência social como fundamentais para o equilíbrio de uma sociedade em ambientes adversos e no enfrentamento de cenários caóticos (VAN BREDA, 2018). Nesse sentido, foi observada junto às prefeituras, a evolução dos gastos com assistência social geral, na intenção de entender se o município foi considerado resiliente ou não.

Foi identificado que apenas o município de Bujaru seguiu um aumento de mais de $70 \%$ com gastos em assistência social, demonstrando os esforços do município em incrementar este setor. Outros dois municípios de Concordia do Pará e Dom Eliseu, também aumentaram significativamente suas despesas com assistência social em relação ao ano de 2019 , concentrando-se em uma média de $42 \%$ de aumento. Os outros municípios não tiveram aumento significativo que pudesse ser relacionado à pandemia.

Em suma, percebe-se que as análises foram direcionadas apenas para alguns municípios considerados outliers no processo resiliente, o que não deveria ser uma exceção. A grande maioria dos municípios analisados seguiu a lógica explicada pela teoria dos ciclos políticos, na qual os gastos públicos são direcionados com base na manutenção do poder.

Como limitação de pesquisa, encontra-se a dificuldade na coleta de dados que não foram divulgados e ainda dificultados para fins desta pesquisa. Como sugestão de pesquisas posteriores, idealiza-se a pesquisa aplicada a uma amostra mais representativa, com foco também nos possíveis fatores motivadores que explicam esta baixa transparência e que sejam considerados também os gastos gerais com saúde.

Entende-se que a pesquisa conseguiu alcançar o objetivo que se propôs ao responder o seguinte problema de pesquisa: a volatilidade dos gastos públicos na área da assistência social e com pessoal no interior do Pará, especificamente na região do Capim, seguiu uma lógica resiliente em contexto de crise? A resposta é não. Apenas 3 municípios puderam demonstrar alguns quesitos resilientes.

\section{Referências:}

ALMEIDA, Helberte João França; GIOVANINI, Adilson. Finanças Públicas Municipais: O comportamento dos gastos com pessoal em um contexto de crise econômica. III Congresso Internacional de Desempenho do Setor Público (CIDEPS). Florianópolis/SC - 2 a 4 de Setembro de 2019.

AQUINO, André C. B. de; CARDOSO, Ricardo Lopes. FINANCIAL RESILIENCE IN BRAZILIAN MUNICIPALITIES. Governmental Financial Resilience: International Perspectives on how Local Governments Face Austerity Public Policy and Governance. Volume 27, 53-71. 
BATISTA, André Pereira; CRUZ, Claudia Ferreira. Resiliência Financeira Governamental: Evidências nos Estados Brasileiros. Revista Cadernos de Finanças Públicas, Brasília, v. 19, n. 3, p. 1-67. 2019.

BERLT, Cristiano; BENDER FILHO, Reisoli; TRISTÃO, Pâmela Amado. Gastos Públicos: análise da aplicacão da lei de responsabilidade fiscal e da constituição federal no corede alto jacuí. Rev. Adm. UFSM, Santa Maria, v. 10, número 1, p. 85-100, JAN. - MAR. 2017.

BRASIL. Ministério da Saúde: Primeiro caso de Covd-19. Disponível em: https://www.gov.br/saude/ptbr/@@search?SearchableText=primeiro+caso+de+covid+no+Brasil. Acesso em: 10/04/2021

Ministério da Saúde: Sobre a doença. Disponível em: https://coronavirus.saude.gov.br/sobre-adoenca\#o-que-e-covid. Acesso em: 10/04/2021

. LEI N 8.742, DE 7 DE DEZEMBRO DE 1993. Dispõe sobre a Organização da Assistência Social e dá outras providências. Disponível em: http://www.planalto.gov.br/ccivil_03/leis//8742.htm. Acesso em $10 / 04 / 2021$.

. Lei Complementar $\mathrm{N}^{\circ} 101$, de 4 de Maio de 2000. Lei de Responsabilidade Fiscal. Disponível em: http://www.planalto.gov.br/ccivil_03/leis/lcp/lcp101.htm. Acesso em: 12/04/2021.

Resolução $n^{\circ}$ 109, de 11 de Novembro de 2009. Tipificação Nacional de Serviços Socioassistenciais. Disponível em: http://www.mds.gov.br/webarquivos/publicacao/assistencia_social/Normativas/tipificacao.pdf. Acesso em: 12/04/2021.

CORDEIRO, Iracema; ARBAGE, Marcelo; Schwartz, Gustavo. Nordeste do Pará: configuração atual e aspectos identitários. In: CORDEIRO, I.M.C.C et al. Nordeste Paraense: Panorama geral e uso sustentável das florestas secundarias. EDUFRA, 2017. p. $19-58$.

DAMAZIO, Caio Lucca. A CALAMIDADE FINANCEIRA DOS ESTADOS: estudo da crise orçamentária de Minas Gerais sob a ótica do gasto com pessoal e seus mecanismos de controle. UNIVERSIDADE FEDERAL DE OURO PRETO. Ouro Preto, MG. 2019.

DALL'ASTA, Denis; FIIRST, Clóvis; OLIVEIRA, Tomas Matheus Giacomel de; SCHIAVO, Priscila dos Santos. CAIR, LEVANTAR E RECUPERAR: RESILIENNCIA FINANCEIRA DOS MUNICÍPIOS PARANAENSES FRENTE A DESASTRES CLIMÁTICOS. Revista Internacional Resiliência Ambiental Pesquisa e Ciência. 2675-3456, v. 1, n. 1, p. 120-135, 2019.

LAKATOS, Eva Maria; MARCONI, Marina de Andrade. Fundamentos de metodologia científica. 5. ed. São Paulo: Atlas, 2003. Disponível em: http://docente.ifrn.edu.br/olivianeta/disciplinas/copy_of_historia-i/historiaii/china-e-india/view. Acesso em: 02/05/2021.

FERNANDES, Gustavo Andrey de Almeida Lopes; PEREIRA; Blenda Leite Saturnino. Os desafios do financiamento do enfrentamento à COVID-19 no SUS dentro do pacto federativo. REVISTA DE ADMINISTRAÇÃO PÚBLICA. Rio de Janeiro 54(4): 595-613, jul. - ago. 2020.

GULLO, MARIA CAROLINA R. (2020). A economia na pandemia Covid-19: algumas considerações. Rosa dos Ventos - Turismo e Hospitalidade, 12 (3 - Especial Covid 19), 1-8. DOI: http://dx.doi.org/10.18226/21789061.v12i3a05.

LIMA, Diana Vaz de; AQUINO, André Carlos Busanelli de. Resiliência $\neg$ financeira de fundos de regimes próprios de previdência em municípios. R. Cont. Fin. - USP, São Paulo, v. 30, n. 81, p. 425-445, set./dez. 2019.

Organização Mundial da Saúde. Surto de doença por coronavírus (covid-19). Disponível em: https://www.who.int/es/emergencies/diseases/novel-coronavirus-2019. Acesso em: 12/04/2021. 
Organização Mundial da Saúde. Perguntas e Respostas sobre a Doença por Coronavirus (covid-19) Disponível em: https://www.who.int/es/emergencies/diseases/novel-coronavirus-2019/advice-for-public/q-acoronaviruses. Acesso em 10/04/2021.

PEREIRA, Carmem. Abordagem Socioeconômica da Mesorregião Nordeste Paraense. In: CORDEIRO, I.M.C.C et al. Nordeste Paraense: Panorama geral e uso sustentável das florestas secundarias. EDUFRA, 2017. p. 97-130.

PRODANOV, Cleber Cristiano; FREITAS, Ernani Cesar de. Metodologia do trabalho científico: métodos e técnicas da pesquisa e do trabalho acadêmico. - 2. ed. - Novo Hamburgo: Feevale, 2013.

RAUPP, F. M.; PINHO, J. A. G. DE. Precisamos evoluir em transparência? - uma análise dos estados brasileiros na divulgação de informações sobre a Covid-19. Gestão e Sociedade, v. 14, n. 39, p. 3725-3739, 1 jun. 2020. Disponível em: https://ges.emnuvens.com.br/gestaoesociedade/article/view/3253. Acesso em: $10 / 02 / 2021$

SECRETARIA DO TESOURO NACIONAL. Manual de contabilidade aplicada ao setor público: aplicado à União, Estados, Distrito Federal e Municípios/ Ministério da Fazenda. 8. ed. Brasília, 2018. Disponível em: https://sisweb.tesouro.gov.br/apex/f?p=2501:9::.:9:P9_ID_PUBLICACAO:31484. Acesso em: 12/04/2021.

SETUR - SECRETARIA DE TURISMO DO ESTADO DO PARÁ. Inventário da Oferta Turistíca do Município de Tomé-Açu-PA. Belém/PA. 2018.2 Disponível em: http://www.setur.pa.gov.br/sites/default/files/inventario_tome_acu_2018-ilovepdf-compressed.pdf. Acesso em: 15/04/2021.

SIQUEIRA, Fernando Faria de. Ciclo Político: Uma Revisão Literária. 2016.

VAN BREDA, Adrian D. A Critical Review of Resilience Theory and its Relevance for Social Work. 54, n. 1, pág. 1-18, 2018. Disponível em <http://www.scielo.org.za/scielo.php?script=sci_arttext\&pid=S0037$80542018000100002 \&$ Ing=en\&nrm=iso $>$. acesso em 29 de maio de 2021. http://dx.doi.org/10.15270/54-1611. 